\title{
Cuidados maternos em ambiente penal: representação por meio de desenho-estória
}

\author{
Maternal care in a prison environment: representation by story drawing
}

Cuidados maternos en la cárcel: representación de la historia a través de dibujos

\author{
Ana Cláudia Rodrigues Ferreira' @ ; Emília Soares Chaves Roubertel @; Daiany Maria Castro Nogueira' @ ; \\ Rebecca Silveira Maial @ ; Edmara Chaves Costal @ ; Maria Isis Freire de Aguiar ${ }^{\prime \prime} @$ \\ 'Universidade da Integração Internacional da Lusofonia Afro-Brasileira; "Universidade Federal do Ceará
}

\begin{abstract}
RESUMO
Objetivo: compreender os sentimentos maternos em relação ao cuidado com o filho dentro da unidade penal. Método: a pesquisa tem abordagem qualitativa. Participaram do estudo gestantes a partir do terceiro trimestre e mães que se encontravam com os filhos no berçário de uma unidade Penal em Aquiráz/Ceará, totalizando 17 participantes nos 9 encontros realizados. A coleta se deu entre junho e outubro de 2018. Foi usada a técnica de Desenho-Estória. A análise dos desenhos foi feita de forma individual com cada detenta e categorizada pelas pesquisadoras. O trabalho obteve aprovação do Comitê de Ética. Resultados: a atividade de Desenho-Estória possibilitou a compreensão do sentimento materno em relação aos cuidados com os filhos e, a partir disso, foi possível a definição de ações vistas como cuidado dentro da unidade. Conclusão: a partir da análise da vivência da maternidade na prisão, é possível a compreensão de sentimentos que perpassam o desenvolvimento do papel materno.
\end{abstract}

Descritores: Assistência de Enfermagem; Saúde da Criança; Enfermagem Materno-Infantil; Prisões.

\begin{abstract}
Objective: to understand mothers' feelings about caring for their children in prison. Method: the participants in this qualitative study were women in the seventh to ninth months of pregnancy, and mothers with children in the nursery, at a Prison Unit in Aquiráz, Ceará, totaling 17 participants in the 9 meetings held. Data were collected between June and October 2018 using the story-drawing technique. The drawings were analyzed individually with each prisoner and categorized by the researchers. The study had research ethics committee approval. Results: the story-drawing activity made it possible to understand how the mothers' felt about caring for their children and, from that, it was possible to specify measures seen as care inside the prison. Conclusion: from analysis of the experience of motherhood in prison, it is possible to comprehend the feelings running through the role of motherhood.
\end{abstract}

Descriptors: Nursing Care; Child Health; Maternal-Child Nursing; Prisons.

\section{RESUMEN}

Objetivo: comprender los sentimientos maternos respecto al cuidado con el hijo dentro de una cárcel. Método: la investigación tiene enfoque cualitativo. Se analizaron mujeres a partir del tercer trimestre de embarazo y madres cuyos hijos se encontraban en la guardería de una prisión en Aquiraz/Ceará, totalizando 17 participantes en los 9 encuentros realizados. La recolección de datos se hizo entre junio y octubre de 2018. Se usó la técnica de historia a través de dibujos. El análisis de los dibujos se hizo de forma individual con cada reclusa y fue categorizado por las investigadoras. El trabajo obtuvo aprobación del Comité de Ética. Resultados: la actividad de historia a través de dibujos posibilitó la comprensión del sentimiento materno respeto al cuidado con sus hijos y, a partir de ello, se hizo posible definir acciones consideradas como atención dentro de la cárcel. Conclusión: a partir del análisis de la vivencia de la maternidad en la prisión, se posibilita la comprensión de sentimientos que atraviesan el desarrollo del rol materno.

Descriptores: Atención de Enfermería; Salud del niño; Enfermería Maternoinfantil; Prisiones.

\section{INTRODUÇÃO}

O elevado índice de mulheres encarceradas traz reflexões acerca da estrutura penal e leis que regem esses estabelecimentos. As prisões, em seu contexto histórico, foram construídas adequadas a um público predominantemente masculino e com o passar dos anos agregou a clientela feminina nas mesmas dependências. Da mesma forma, as leis que regiam esses estabelecimentos, se referiam a um contexto masculinizado, não contemplando as necessidades femininas, a exemplo da maternidade.

Nesse contexto, reflete-se sobre o desenvolvimento do papel da mãe em relação aos cuidados com o filho no sistema penal e as consequências do aprisionamento indireto para a criança. A proposta desse estudo tem por objetivo compreender os sentimentos maternos em relação ao cuidado com o filho dentro da unidade penal. Entender o ambiente e a visão do público ajuda a traçar estratégias para a implementação de cuidados efetivos e melhoria da qualidade de vida das pessoas envolvidas.

Autora correspondente: Ana Cláudia Rodrigues Ferreira. E-mail: claudiaf048@gmail.com 


\section{REFERENCIAL TEÓRICO}

O ambiente penal oferece diversas limitações para o desenvolvimento da criança, como o ambiente físico limitado, as regras incidentes sobre as mães que afetam os filhos, a limitação de contato com outros membros da família, dentre outros. Nesse contexto, a presença e o cuidado da mãe é uma forma de minorar fatores que contribuem negativamente para o desenvolvimento na infância, fazendo-se necessário a compreensão desta sobre os fatores e consequências para a saúde da criança. Um estudo que compara a realidade de mães presidiárias brasileiras e portuguesas e refere-se à dificuldade em exercer a maternidade sozinha e os desafios de cuidar dos filhos, bem como as interferências do ambiente penal na vida e comportamento da criança ${ }^{1}$.

Convém compreender melhor qual a vivência das mulheres sobre a maternidade dentro do cárcere. Com um entendimento mais próximo da realidade dessas mulheres/mães é possível o planejamento de um apoio direcionado na tentativa de minimizar os efeitos psicológicos trazidos pela condição vivenciada. A princípio convém compreender, à luz do método fenomenológico, quais os sentimentos maternos em relação ao cuidado com o filho. Para uma visão mais próxima da realidade utilizou-se a fenomenologia social de Alfred Schütz, que trata das questões com caráter interpretativo e compreensivo, atribuindo significado ao mundo cotidiano de acordo com as experiências de seres que se relacionam entre si e de acordo com as projeções de cada um sobre a realidade ${ }^{2}$. Alfred Schütz (1899-1959) era austríaco e, através das ciências sociais e da fenomenologia, buscou estabelecer os fundamentos de uma sociologia fenomenológica compreensiva, elaborando uma teoria que propõe a análise das relações sociais mútuas que envolvem pessoas. Nessas relações há uma interação entre a consciência e a ação, o que confere características próprias e significados distintos em cada relação entre os sujeitos ${ }^{3}$.

O sentimento da mãe em relação ao cuidado com os filhos no contexto penal, pode trazer interferências de uma gama de novas relações sociais proporcionada pelo ambiente. Essas interações sociais ficam limitadas à criança, que passa a ser um suporte emocional para a mãe; as detentas, que podem vir a se tornar novas figuras de referência para o cuidado com o filho; as agentes penitenciárias, que mantém uma relação menos amigável por questão de ordem e segurança; e com os familiares, apenas nos dias de visita.

\section{MÉTODO}

Foi realizada uma pesquisa de campo com abordagem qualitativa e o objetivo foi exploratório, pois visou se familiarizar com a questão de pesquisa, a saber: quais os sentimentos das mães em relação ao cuidado com o filho em um ambiente penal? Esta pesquisa faz parte de um estudo maior e as informações coletadas aqui serviram de base para intervenções posteriores feitas pelas pesquisadoras.

O estudo foi realizado em um Instituto Penal Feminino (IPF), única penitenciária feminina do estado do Ceará, localizada no município de Aquiraz, região metropolitana de Fortaleza, com capacidade para abrigar 374 detentas.

A penitenciária tem uma estrutura comum para abrigar presas em geral que conta em seu interior com uma unidade de saúde. Em uma estrutura anexa à unidade penal encontra-se o berçário que abriga gestantes em estágio final da gestação e mães acompanhadas de crianças por tempo determinado pelo Estado e pela unidade penal.

O estudo foi realizado com gestantes e mães. Foram incluídas mães que estavam com filhos no berçário da penitenciária e as gestantes a partir do terceiro trimestre gestacional e que também se encontravam no berçário. Estas eram transferidas para o berçário por ser um ambiente mais tranquilo e acolhedor pra se vivenciar o estágio final da gestação, comparado ao clima de tensão das celas dos pavilhões comuns.

Foram excluídas do estudo gestantes e mães que estavam em isolamento por questões de segurança nos períodos da coleta. Devido à grande rotatividade das detentas dentro do berçário, não foi possível avaliar sempre as mesmas detentas, dessa forma, o estudo contou com 17 participantes. A rotatividade se dá porque as mulheres saem da unidade por serem separadas dos filhos ou receberem liberdade provisória e entram no berçário pela progressão da gestação e necessidade de saída das alas comuns.

As participantes do estudo foram selecionadas por meio de amostra probabilística, no qual o pesquisador determinou as participantes de acordo com sua subjetividade, experiências e objetivos da pesquisa ${ }^{4}$. Participaram do estudo 04 (quatro) gestantes e 13 (treze) mulheres que se encontravam com os filhos no berçário; se recusaram a participar do estudo 02 mulheres (mães). Foi observado que o principal questionamento era se a atividade seria levada até o juiz, podendo interferir no tempo de pena. A coleta de dados foi realizada entre junho e outubro de 2018.

A maior frequência de idade entre as detentas deste estudo está entre 20 e 29 anos (70,5\%). Quanto à cor, 70,7\% das mulheres referiram ser pardas. Quanto ao número de filhos, $82,4 \%$ possuem mais de um filho. Significando a quebra de vínculos familiares quando da pena privativa de liberdade. Quanto ao nível de escolaridade, $64,7 \%$ tinham o fundamental incompleto, $23,6 \%$ o médio completo e $11,7 \%$ o médio completo. 
Para coletar os dados, foi utilizada a técnica do Desenho-Estória(D-E), para que as mulheres representassem os cuidados com seus filhos. Os desenhos livres ou temáticos demonstram as expressões das pessoas não da forma consciente como se apresentam, mas interpretadas de acordo com alguma conceituação preestabelecida psicologicamente. Para captação desses desenhos foram fornecidos uma folha de papel A4 em branco e lápis de cera. Para nortear a elaboração do desenho foi fornecida a seguinte instrução: faça um desenho representando o seu cuidado com o seu filho dentro da unidade penal. Em seguida as interpretações das mães foram discutidas individualmente e, posteriormente, foi realizada uma análise categorizada pelas pesquisadoras.

A interpretação dos desenhos ocorreu em um momento individual, onde cada participante mostrou seu desenho para as pesquisadoras e explicou os motivos de tal representação. A partir das interpretações das explicações das detentas e da posterior análise categorizada dos desenhos, ocorreram as definições de temáticas trabalhadas em estudo posterior com as participantes. Para a coleta dos desenhos foram realizados dois encontros e para a realização das intervenções provenientes das interpretações conjuntas dos desenhos foram realizados mais sete encontros.

Os encontros continham a presença das mulheres e das três pesquisadoras, não contando com a presença de agentes penitenciárias, dada a pouca hostilidade atribuída a essas detentas. Como instrumentos de coleta foram utilizados diário de campo para registro, bem como folhas e giz de cera para captação dos desenhos. Como regra, a gestão da penitenciária não autorizou nenhum dispositivo audiovisual ou materiais perfurocortantes que trouxessem algum risco para as detentas e pesquisadoras. Cada encontro teve duração média de 45 minutos, não sendo necessária reabordagem de conteúdo nessa etapa de Desenho-Estória.

A pesquisa atendeu as normas da resolução $n^{\circ} 466 / 2012$ do Conselho Nacional de Saúde-CNS, prezando pelos preceitos da bioética (autonomia, não maleficência, beneficência, justiça e equidade) ${ }^{4}$. Foi aprovada sob o número 2.468.623 no Comitê de Ética em Pesquisa da UNILAB - Universidade da Integração Internacional da Lusofonia AfroBrasileira. Todos os participantes assinaram o Termo de Consentimento Livre e Esclarecido (TCLE).

\section{RESULTADOS E DISCUSSÃO}

A técnica projetiva do Desenho-Estória é advinda da psicologia clínica e estimula o diálogo e a apreensão do conteúdo não expressado de forma verbal sobre determinado objeto social. Sua aplicação permite a apreensão de subjetividades vivenciadas no contexto relacional em suas múltiplas facetas e a expressão de enunciados atrelados aos fatos e acontecimentos atualizados ${ }^{5}$.

A abordagem foi feita cela a cela, pois dessa forma haveria uma apresentação das pesquisadoras e do objetivo da pesquisa para um menor número de mulheres, facilitando a compreensão. Por conta do baixo grau de escolaridade e dificuldades para escrever, foi solicitado que as detentas explicassem o desenho verbalmente em vez de escreverem a história explicativa.

A seguir será apresentada a análise individual (quando um mesmo desenho traz uma variedade de informações ou trata de um assunto específico) ou categorizadas (quando os desenhos apresentam muitos pontos comuns).

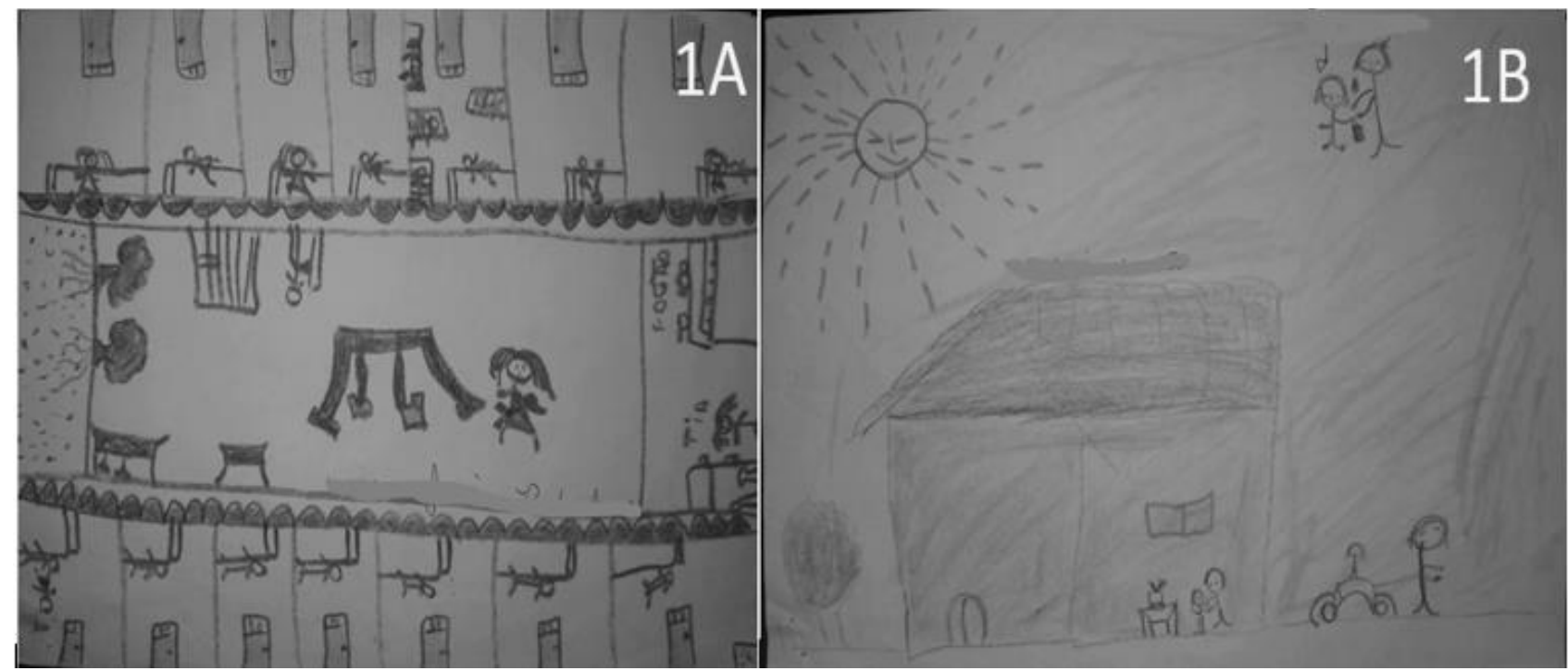

FIGURA1: Representação do interior e do exterior do berçário, Aquiraz,CE, Brasil, 2019. 
Na figura 1 desenho A, a detenta explicou que esse é o berçário da penitenciária. Em cada cela tem crianças deitadas nas camas porque elas dividem a mesma cama com a mãe. Quando questionada sobre quem estava na cozinha, a detenta falou que era a tia e explicou que era uma das detentas mais antigas da unidade do berçário. Houve um destaque na fala para a presença da agente penitenciária.

A detenta representou todo o berçário da unidade penal. É possível perceber a representação de crianças dormindo e dos momentos de diversão nos brinquedos que existem dentro do berçário. Durante as visitas à unidade foi percebido que, frequentemente, existem várias crianças no pátio, onde ficam os brinquedos, e algumas vezes uma das mães fica cuidando dessas crianças, como foi bem representado no desenho. O repouso das crianças ocorre, como foi representado na Figura 1, na mesma cama em que a mãe dorme, porém em todos os relatos as mães referem sono prejudicado por preferir favorecer o conforto do filho diante do espaço pequeno. Fato notório no desenho é a superlotação em uma das celas, o que também foi percebido como realidade em todas as celas durante as visitas à unidade para os encontros de educação em saúde.

Na explicação da detenta, ela relata que desenhou a si mesma na cozinha da unidade e que as outras detentas a chamam de tia, explicando que ela é uma figura de referência para apoio às demais mulheres do berçário (essa detenta teve liberdade condicional concedida antes do término desta pesquisa).

A figura 1 desenho B representa a visão externa do berçário. A detenta explicou que desenhou momentos de brincadeiras com o filho e o cuidado com a alimentação.

É possível notar representações semelhantes às já avaliadas na Figura 1 desenho A, como os momentos de lazer no pátio do berçário e as árvores ao redor da estrutura. Na parte superior da foto está ilustrado o cuidado da mãe em relação à alimentação da criança.

A representação lembra um ambiente doméstico, com janelas e portas sem grades e uma sala com televisão. Esse fato é reforçado pela ausência da agente penitenciária na figura, o que pode ser justificado pelo maior afeto criado entre agentes que ficam no berçário e detentas, tornando a visão do ambiente menos hostil. Um trabalho realizado com agentes penitenciárias apresenta que há o desenvolvimento de um sentimento positivo em relação às mães que tem consigo bebês na prisão. No entanto mesmo desenvolvendo vínculos positivos com as presas, os profissionais tendem a personificar a função jurídica do Estado. É relatada a falta sentida quando ocorre transferência das detentas, porém esse sentimento é aceito por ser dirigido especificamente aos bebês, tornando-se socialmente mais compreensível. ${ }^{6,7}$

Apesar das orientações sobre a representação dos cuidados aos filhos que se encontravam dentro da unidade penal, as mulheres sentiram necessidade de expressar sobre liberdade, sobre o sentimento para com os outros filhos que se encontravam fora da unidade penal, como representado na Figura 2 desenhos C, D, E e F.

Essa é casa da família, afirmou a detenta que desenhou a figura 2 desenho $C$. Foi mencionado o bairro onde se localiza e que os outros dois filhos ainda moram lá com a avó. Esse é um momento de diversão com os filhos reunidos.

Na Figura 2 desenho $D$ estão desenhados a detenta, a filha que se encontra com ela na penitenciária e os dois filhos que estão com a família. Ela escreveu no próprio desenho "meus cuidados com meus filhos são de uma mãe amorosa, banho, alimento, brinco, tudo na sua hora. Por eles eu mato e morro." Foi falado sobre a esperança de estar junto com todos os filhos brevemente e o desejo de não errar mais para não ser privada do convívio com eles novamente. Entende-se que, mesmo em condições adversas, a vida dessas mulheres sofre uma reestruturação após a maternidade, à medida que suprem as próprias necessidades com os filhos. ${ }^{8}$

Antes do término desta pesquisa ela recebeu progressão de regime e saiu em liberdade. Enquanto esteve na unidade era uma aliada no convite às outras mães para as atividades de educação em saúde.

A figura 2 desenho E mostra ela (detenta) e os três filhos. A detenta refere que seria um momento de passeio com eles e que ela gostava desses momentos de diversão com os filhos. Explicou que a filha menor foi desenhada com uma bola na barriga porque ela é "gordinha" e todos falam que ela é obesa.

Na Figura 2 desenho F estão representados os quatro filhos e a detenta em momentos de diversão. Ela escreve: "liberdade para nós. Estamos chegando." Refere-se ao desejo de estar em casa na companhia dos outros filhos.

Após a orientação inicial, a atividade foi realizada sem intervenção das pesquisadoras. Percebe-se, por meio dos desenhos, que a maternidade transcende as grades da prisão, visto que, ao se referir a cuidados maternos, todos os filhos são representados com a mesma proximidade, estando dentro ou fora da penitenciária.

Essa referência aos filhos extramuro pode decorrer do fato de muitas mulheres serem responsáveis pela criação dos filhos e pela manutenção da casa, antes de serem presas. O encarceramento piora a situação financeira da família, fragiliza os vínculos com os filhos e impulsiona uma nova organização familiar. Apesar do enfraquecimento dos vínculos afetivos, estudos demonstram que a dor pela ausência dos filhos se ameniza pela ciência de que os filhos estão melhores, se mantidos afastados do ambiente penal. Ocorre dessa forma uma terceirização das funções maternas externas ${ }^{9,10}$. 


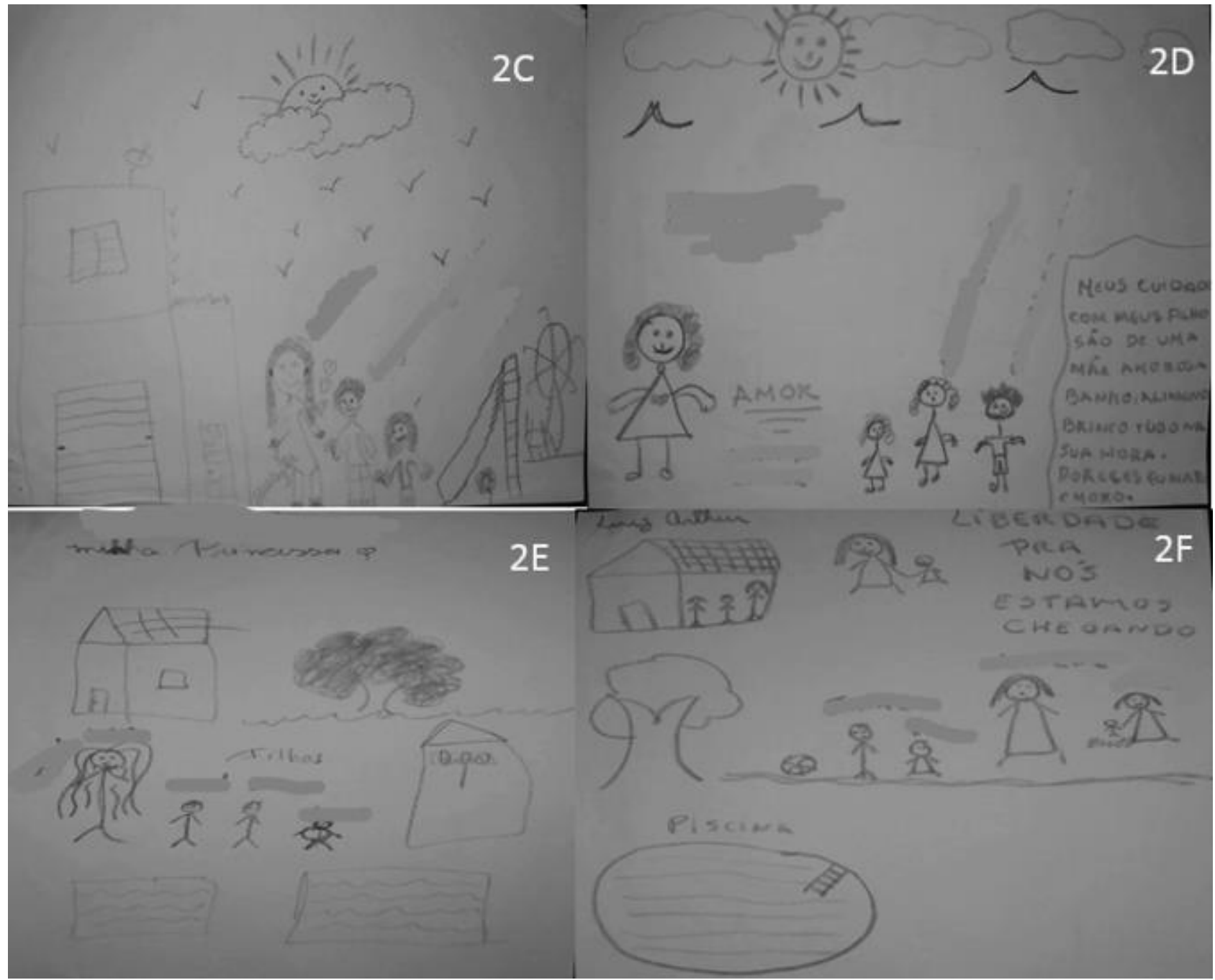

FIGURA 2: Representação dos ambientes externos de convivência familiar antes da detenção. Aquiraz,CE, Brasil, 2019

As figuras precedentes demonstram uma perspectiva positiva em relação ao futuro fora dos muros da prisão e próxima aos filhos, sentimento que foi referido pelas mães na explicação dos desenhos e foi percebido em todos os contatos posteriores com as detentas. Essa percepção corrobora com os resultados de outro estudo quando referem que a principal motivação das mulheres para a saída da prisão é o reestabelecimento dos vínculos afetivos com os filhos $^{10}$. Esse desejo motiva o trabalho e o bom comportamento na prisão e as tornam capazes de enfrentar as adversidades vividas na unidade penal. ${ }^{11}$

Outro fator comum a todos os desenhos é a representação de diversão, com elementos como piscina, parques de diversões e a presença de um ambiente ensolarado e cheio de vida. Essa representação está relacionada com a esperança pela liberdade, sentimento que também pode ser percebido durante o contato com as internas, bem como foi representado em $44,4 \%$ dos desenhos.

Reafirmando essa ideia, um estudo mostra que as detentas estão cotidianamente presentes nas famílias, pois é necessária logística financeira e de solidariedade e auxílio para com a pessoa presa e organização para o cuidado com os filhos e o lar "do lado de fora"12. A necessidade emocional de representações como as dos desenhos anteriores advém da preocupação com o que ficou externo aos muros da penitenciária.

A representação da mulher como nutriz ou provedora da alimentação dos filhos se expressa na figura 3 nos desenhos G, H el.

A figura 3 desenho $\mathrm{G}$ mostra um cuidado que a detenta terá com o filho, representando a amamentação. No início desta pesquisa, essa participante estava gestante. A princípio se recusou a participar das atividades, mas, posteriormente, decidiu integrar-se ao estudo após ver outras mulheres participando. 

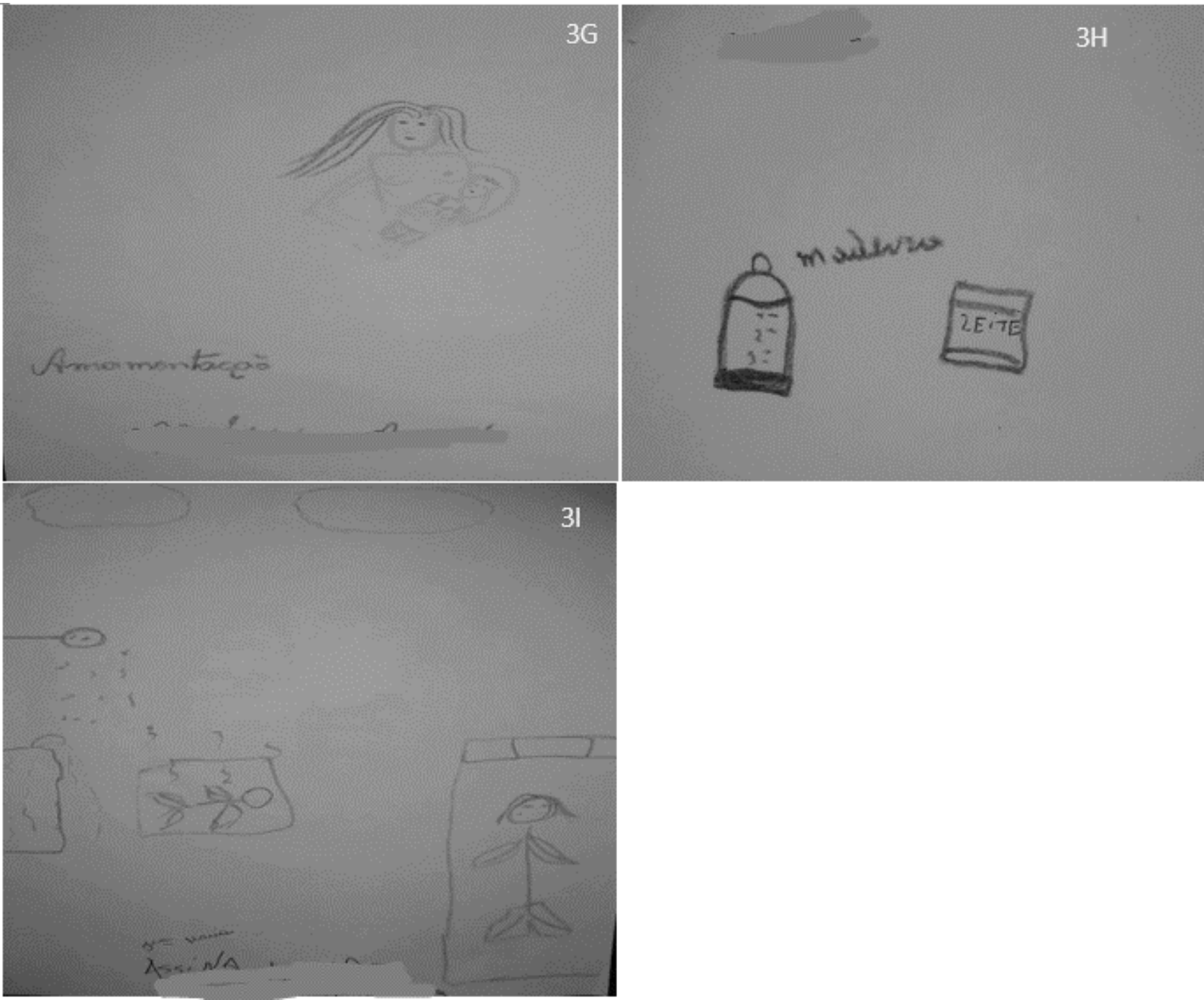

Figura 3: Representação dos cuidados com alimentação e banho da criança. Aquiraz, CE, Brasil, 2019

A amamentação foi representada apenas uma vez, porém foi percebido que todas as detentas da unidade amamentavam. Inclusive foi detectada amamentação cruzada já no primeiro dia de visita à unidade.

Em um estudo realizado em cidades do sudeste do Brasil, conclui-se que "o aleitamento cruzado foi mais praticado pelas populações mais vulneráveis: mães adolescentes, com baixa escolaridade, com menor nível socioeconômico, com número insuficiente de consultas pré-natais e primíparas". Além de estarem no rol de populações vulneráveis, as detentas apresentam parte das características que foram detectadas na população em geral (baixa escolaridade e baixo nível socioeconômico) ${ }^{13}$.

Na Figura 3 desenho H está representado o cuidado referente ao preparo dos alimentos para a criança. A partir do desenho buscou-se compreender melhor o processo de dispensação de alimentos para a unidade. A detenta explicou quais os tipos de produtos eram disponibilizados, com que frequência e estimando uma quantidade.

A figura 3 desenho $\mathrm{H}$ traz uma representação explícita da alimentação complementar. Semanalmente, é dispensada à unidade alimentos como: leite, massas, verduras, temperos prontos, dentre outros, que são para consumo exclusivo das crianças, visto que a comida para as mães vem da cozinha da penitenciária sendo fornecida diariamente em horários pré-determinados. Porém, foi referido diversas vezes que essa alimentação não é suficiente para uma semana, referindo-se como principal problemática o fato de as próprias mães consumirem os alimentos.

Durante a explicação desse desenho foi questionado sobre o preparo dos alimentos e encontrados diversos equívocos quanto à forma de preparo para crianças, como exemplo o uso de temperos prontos em detrimento dos naturais. 
É importante destacar que a aquisição de bons hábitos alimentares tem como maior influência a interação da criança com a mãe, o ambiente doméstico e as condições socioeconômicas ${ }^{14}$. Apesar de as condições prisionais determinarem os tipos de alimentos disponíveis, torna-se importante que as mães tenham a consciência de proporcionarem hábitos alimentares o mais saudavelmente quanto possível.

A figura 3 desenho I reproduz o momento do banho e de dormir da criança. A partir dele, aproveitou-se para compreender melhor como era realizado o banho e ela (detenta) nos levou para conhecer o banheiro da cela.

A Figura 3 desenho I representa dois cuidados relacionados à criança: o banho e o sono. A partir de observação das pesquisadoras foi detectado que os recém-nascidos tomam banho por aspersão, em decorrência da falta de lugar adequado dentro das celas para um banho de imersão dos bebês. As detentas mais antigas referem que banham as crianças das detentas mais jovens com filhos recém-nascidos por terem mais habilidade para segurar a criança embaixo do chuveiro.

Durante a explicação do desenho foi questionado sobre a higiene em geral e percebidas dúvidas em relação à limpeza do coto umbilical. Notou-se a crença do uso de objetos sobre o coto umbilical, justificada pelo uso nos filhos anteriores. O conhecimento de puérperas internadas em um alojamento conjunto acerca da higiene do neonato, quando abordado em outro estudo, também encontrou que "a maioria das puérperas acreditava ser necessária a cobertura do coto com curativos ou faixas e desconheciam os produtos adequados para esta higienização". Sendo fundamental a orientação das mães, mesmo as que são multíparas ${ }^{15}$.

A partir da análise das figuras e das explicações fornecidas pelas detentas, bem como pela análise das pesquisadoras, foi possível a delimitação dos seguintes cuidados relacionados à criança em ambiente penal: cuidados com aleitamento materno; cuidados com alimentação complementar; cuidados com o ambiente em que vive, sono e repouso; cuidados com a higiene da criança.

\section{Limitações do estudo}

As limitações deste estudo se deram pelas restrições do ambiente penal na entrada com materiais. Dessa forma pode ser disponibilizado somente papel e giz de cera para que as mulheres realizassem os desenhos. Houve também a resistência de algumas mulheres na participação do estudo. Percebe-se que a criação de vínculo com as detentas é mais demorada. Algumas mulheres se sentiram tímidas em realizar o desenho ou sentiram medo de que o desenho fosse destinado ao juiz e interferisse no tempo de condenação e, mesmo após a explicação da finalidade da pesquisa, algumas mantiveram a decisão de não participar.

\section{CONCLUSÃO}

A partir da análise da vivência da maternidade na prisão, é possível a compreensão de sentimentos que perpassam o desenvolvimento do papel materno que se encontra limitado para a maioria das mulheres, haja vista que a maior parte tem filhos fora da prisão. Para o cuidado de enfermagem é importante entender a concepção que as mulheres têm sobre o cuidado com os filhos que se encontram sob seus cuidados na unidade, bem como saber como elas se veem desenvolvendo esses cuidados, a fim de melhor orientar partindo dos conhecimentos prévios das mulheres e dentro das limitações próprias do ambiente, ou seja, haverá norteamento das intervenções de enfermagem.

\section{REFERÊNCIAS}

1. Mello DC. A maternidade no meio prisional: vivências de mães encarceradas na realidade brasileira e portuguesa. Editora Lumen Juris. Rio de Janeiro. 2016.

2. Muñoz SSI, Fernandes, APM. Principais doenças causadas por ectoparasitas. Desenvolvimento de material didático ou instrucional - Folleto Educativo. 2013.

3. Zeferino MT, Carraro, TE. Alfred schütz: from theoretical-philosophical framework to the methodological principals of phenomenological research. Texto contexto - enferm. [Internet]. 2013 [cited 2019 Jul 15]; 22(3):826-34. DOI: http://dx.Doi.Org/10.1590/s0104-07072013000300032.

4. Ministério da Saúde (Br). Conselho Nacional de Saúde. Resolução no 466, de 12 de dezembro de 2012. [cited 2020 Sep 11]; Available from: http://bvsms.saude.gov.br/bvs/saudelegis/cns/2013/res0466_12_12_2012.html.

5. Moscovici S. Representações sociais: investigações em psicologia social. Psicologia social. $10^{\text {st }}$ ed. Rio de Janeiro: Vozes. 2013.

6. Barcinski M, Altenbernd B, Campani C. Between caring and monitoring: ambiguities and contradictions in the discourse of a female penitentiary officer. Ciência \& Saúde Coletiva [Internet]. 2014 [cited 2019 Jul 15]; 19(7):2245-54. DOI: https://doi.Org/10.1590/1413-81232014197.09892013.

7. Flores NMP, Smeh LN. Arrested mothers, helpless children: motherhood and interpersonal relationships in prison. Physis: Revista de Saúde Coletiva [Internet]. 2018 [cited 2019 Jul 15]; 28(4):e280420. DOI: http://dx.Doi.Org/10.1590/s010373312018280420. 
8. Oliveira LV, Costa GMC, Miranda FAN. The meaning of motherhood for prisoners. Rev. enferm. UFPE on line. [Internet]. 2015 [cited 2019 Jul 15]; 9(supl. 2):851-7. Available from:

https://periodicos.ufpe.br/revistas/revistaenfermagem/article/download/10409/11183.

9. Diuana V, Correa MCDV, Ventura M. Women in brazilian prisons: tensions between punitive disciplinary order and maternity prescriptions. Revista de Saúde Coletiva [Internet]. 2017 [cited 2019 Jul 15]; 27(3):727-47. DOI: https://doi.Org/10.1590/s010373312017000300018.

10. Soares IR, Cenci CMB, Oliveira LRF. Mothers in prision: link perception with sons. Estudos e Pesquisas em Psicologia [Internet]. 2016 [cited 2019 Jul 15]; 16(1):27-45. Available from: http://pepsic.bvsalud.org/scielo.php?script=sci_arttext\&pid=S180842812016000100003.

11. Pereira TG, Reis AOA. Professional representations about babies in prison context. Trabalho, Educação e Saúde [Internet]. 2020 [cited 2019 Jul 15]; 18(3):e00306138. DOI: http://dx.Doi.Org/10.1590/1981-7746-sol00306.

12. Pereira EL. Families of incarcerated women, health promotion and access to social policies in the federal district, brazil. Ciênc. saúde coletiva [Internet]. 2016 [cited 2019 Jul 15]; 21(7):2123-34. DOI: Http://dx.Doi.Org/10.1590/141381232015217.16792015.

13. Von Seehausen MP, Oliveira MIC, Boccolini CS. Factors associated with cross-nursing. Ciênc. saúde coletiva [Internet]. 2017 [cited 2019 Jul 15]; 22:1673-82. DOI: Http://dx.Doi.Org/10.1590/1413-81232017225.16982015.

14. Martins ML, Haack A. maternal knowledge: influence in introduction of complementary feeding. Com. Ciências Saúde [Internet]. 2012 [cited 2019 Jul 15]; 23(3):263-70. Available from: http://bvsms.saude.gov.br/bvs/periodicos/revista_ESCS_v23_n3_a8_conhecimentos_maternos_influencia.pdf.

15. Andrade LCO, Santos MS, Aires JS, Joventino ES, Dodt RCM, Ximenes LB. New mothers' knowledge about hygiene for newborns. Cogitare Enferm. [Internet]. 2012 [cited 2019 Jul 15]; 17(1):99-105. DOI: http://dx.Doi.Org/10.5380/ce.V17i1.26381. 